\title{
Characterization of ferredoxin and flavodoxin as markers of iron limitation in marine phytoplankton
}

\author{
Deana L. Erdner ${ }^{1}$, Neil M. Price ${ }^{2}$, Gregory J. Doucette ${ }^{3}$, M. Luisa Peleato ${ }^{4}$, \\ Donald M. Anderson ${ }^{1, *}$ \\ 'Department of Biology, Woods Hole Oceanographic Institution, Woods Hole, Massachusetts 02543, USA \\ ${ }^{2}$ Department of Biology, McGill University, Montreal, Québec H3A 1B1, Canada \\ ${ }^{3}$ NOAA/NOS, Charleston Laboratory, 219 Fort Johnson Road, Charleston, South Carolina 29412-9110, USA \\ ${ }^{4}$ Departamento de Bioquimica y Biologia Molecular y Celular, Facultad de Ciencias, Universidad de Zaragoza, \\ E-50009 Zaragoza, Spain
}

\begin{abstract}
Under conditions of iron stress, many organisms replace the common iron-sulfur redox protein ferredoxin with flavodoxin, a functionally equivalent, non-iron-containing protein. These 2 proteins have been proposed to be indicators of iron nutritional status in marine phytoplankton, but little is known of their expression and regulation. This study characterized their expression by: (1) testing 17 marine phytoplankton isolates from 4 different algal classes for their ability to induce flavodoxin under iron limitation. (2) determining the effect of ecologically relevant limiting factors (other than iron) on flavodoxin expression using the marine centric diatom Thalassiosira weissflogii as a model organism, and (3) examining, in detail, the relationship between iron availability and relative ferredoxin/flavodoxin abundance again using $T$ weissflogii as a model. In the organisms examined, the most common response (12 of 17 isolates) to iron limitation was induction of flavodoxin and suppression of ferredoxin expression. The remaining 5 isolates, largely of coastal origin, were never observed to produce flavodoxin. These 5 non-inducing organisms have been shown to have high intrinsic Fe requirements for growth and should therefore not present a problem for field measurements of ferredoxin and flavodoxin in iron-poor areas. Expression of flavodoxin in $T$ weissflogii was found to be specific to iron limitation, and was not induced by nitrate, phosphate, silicate, zinc or light deficiency. The prevalence of the flavodoxin response and its insensitivity to other limiting factors support its use as an indicator of the presence of iron limitation. Iron regulation of relative ferredoxin and flavodoxin abundance (the Fd index) and iron availability was examined in greater detail by measuring the Fd index in $T$. weissflogii grown over a range of limiting iron concentrations. The relationship between Fd index and growth rate (a proxy for iron availability) is composed of 2 distinct regions. In the first region, at low growth rates, ferredoxin is undetectable and the Fd index is uniformly zero. In the second region, at moderate-to-fast growth rates, ferredoxin and flavodoxin co-occur in the cells. This implies that flavodoxin substitution is not a simple 'on-or-off' response. Flavodoxin expression is also very sensitive to iron limitation, occurring even at fast growth rates $\left(80\right.$ to $\left.90 \% \mu_{\max }\right)$. When the 2 proteins co-occurred in cells, their relative abundance (the Fd index) tended to increase along with increasing iron availability. Thus, variation in the Fd index has the potential to indicate spatial and temporal changes in the severity of iron stress in the phytoplankton community.
\end{abstract}

KEY WORDS: Ferredoxin Flavodoxin - Iron · Phytoplankton

\section{INTRODUCTION}

The potential for iron limitation of oceanic primary productivity has generated considerable controversy since it was proposed by Martin and colleagues

-Addressee for correspondence. E-mail: danderson@whoi.edu
(Martin \& Fitzwater 1988, Martin et al. 1989, 1990a,b, Martin 1990). Resolution of this debate has been hindered in part by a lack of suitable techniques for the assessment of iron limitation. The bulk of the evidence in support of iron limitation is derived from nutrient addition bioassays, in bottles (e.g. Buma et al. 1991, Coale 1991) and in the environment (Martin et al. 
1994, Coale et al. 1996). The interpretation of bottle bioassays is complicated by the potential for contamination and confinement effects (e.g. Venrick et al. 1977, Cullen 1991) and mesoscale enrichments are expensive and logistically difficult. The methodological problems associated with these approaches could be circumvented through the use of a diagnostic indicator - a specific cellular response that is directly regulated by iron availability. Such an indicator would allow rapid diagnosis of iron limitation without manipulation of the natural community.

The proteins flavodoxin and/or ferredoxin have been proposed as markers of iron limitation (LaRoche et al. 1995, Doucette et al. 1996). Flavodoxin is induced in response to iron stress as a functional replacement for the iron-sulfur protein ferredoxin, which cells utilize when iron is not limiting growth. This adaptation is common among bacteria and freshwater algae, where it has been studied for decades (e.g. Vetter \& Knappe 1971, Zumft \& Spiller 1971, Fillat et al. 1988), but exceptions do exist. Various strains of the freshwater cyanobacterium Anabaena show 3 different modes of induction: Anabaena ATCC29413 induces flavodoxin when iron limited (Fillat et al. 1988), Anabaena ATCC29211 does not produce flavodoxin (Pardo et al. 1990), whereas Anabaena ATCC29151 produces flavodoxin constitutively in its heterocysts (Sandmann et al. 1990). Light is able to modulate the ferredoxin gene expression in both pea and wheat (Dobres et al. 1987 , Bringloe et al. 1995). In the freshwater cyanobacterium Synechocystis the flavodoxin protein seems to function as a general stress response, accumulating under conditions of high salt, heat shock and iron limitation (Fulda \& Hagemann 1995).

Comparatively little is known about ferredoxin and flavodoxin expression and regulation in marine phytoplankton. A few laboratory studies to date document flavodoxin induction in a small number of marine microalgae (LaRoche et al. 1993, 1995, Doucette et al. 1996), of which all except 1 were diatoms. Information on environmental regulation of ferredoxin and flavodoxin expression is similarly scarce. The study of flavodoxin regulation in marine algae has primarily concerned its response to iron, although it has been demonstrated that nitrogen or phosphorus limitation does not induce flavodoxin expression in the marine diatom Phaeodactylum tricornutum (LaRoche et al. 1993). However, the latter study is the extent of the present knowledge of non-iron flavodoxin regulation in marine phytoplankton.

Before flavodoxin and ferredoxin can be used reliably as indicators of iron limitation in the ocean their expression must be better characterized in marine phytoplankton. Criteria for such a characterization were detailed by Falkowski et al. (1992): 'To be useful, diagnostic tools must identify those processes that (1) impose a truly physiological limitation, (2) are uniquely affected by a specific limiting factor, (3) are broadly applicable across phylogenetic lines, and (4) can be used in the field.' This study addresses the second and third of these criteria - the specificity of the flavodoxin response for iron limitation and occurrence of flavodoxin expression in diverse algal classes.

Our investigation proceeded along 3 lines. The first, a phylogenetic survey, examined expression of both ferredoxin and flavodoxin in a number of marine phytoplankton cultures representing different taxonomic groups to determine the generality of the flavodoxin substitution strategy. The second, a nutrient limitation study, employed the marine centric diatom Thalassiosira weissflogii as a model system to determine the effect of nitrate-, phosphate-, silicate-, iron-, light- or zinc-deficiency upon ferredoxin and flavodoxin protein expression. Finally, iron regulation was examined in detail by measuring relative cellular ferredoxin and flavodoxin abundance in $T$. weissflogil grown at various iron levels. Together, these data provide a thorough assessment of ferredoxin and flavodoxin regulation in marine phytoplankton.

\section{MATERIALS AND METHODS}

Cultures. Organisms used in this study and their clone designations are listed in Table 1. All strains are listed by their CCMP number except for Chaetoceros neogracile, which was obtained from the Milford Collection, NMFS, Milford, CT, USA. In addition to the commercially available organisms, 3 pennate diatoms designated as 'EqPac pennate diatom sp.' were also examined. These 3 clones were isolated by E. Mann from the iron-fertilization-induced pennate diatom bloom during the IronEx II experiment (Coale et al. 1996) and rendered clonal via single-cell isolation by D.L.E. They are identified here by their clone numbers, $\mathrm{A} 3-30,10-40 \mathrm{~A}$ and $7-47 \mathrm{~B}$, pending further taxonomic identification. Although sterile techniques were used to minimize bacterial contamination, the cultures were not axenic

Culture conditions-phylogenetic survey. All cultures, except Synechococcus DC2 were grown in a modification of ESNW medium as described previously (Doucette et al. 1996). Cultures of Synechococcus DC2 were not grown by the authors, but were a gift from the University of Warwick and supplied as freeze-dried cell pellets.

$\mathrm{Fe}$ addition to replete cultures was $5 \times 10^{-6} \mathrm{M} \mathrm{Fe} /$ $50 \times 10^{-6}$ M EDTA for all organisms except for Thalassiosira weissflogii, which was grown at $50 \times 10^{-6} \mathrm{M} \mathrm{Fe} /$ $500 \times 10^{-6} \mathrm{M}$ EDTA. Iron additions to iron-deplete cul- 
Table 1. List of organisms examined in this study, their algal class, clone designation, isolation locale (classified as $N$-neritic or O-oceanic) and presence (+) or absence (-) of flavodoxin induction in response to iron limitation

\begin{tabular}{|c|c|c|c|c|}
\hline & Clone & Location & Habitat & Flv ${ }^{a}$ \\
\hline \multicolumn{5}{|l|}{ Dinophycede } \\
\hline Alexandrium fundyense & CCMP 1312 & Gulf of Maine, $43^{\circ} 00^{\prime} \mathrm{N}, 70^{\circ} 19^{\prime} \mathrm{W}$ & $\mathrm{N}$ & - \\
\hline Amphidinium carterae & CCMP1314 & Great Pond Falmouth, MA, USA & $\lambda$ & + \\
\hline Symbiodinium microadriaticum & CCMP829 & Great Barrier Reef, Australia & $\lambda$ & + \\
\hline \multicolumn{5}{|l|}{ Bacillariophyceae } \\
\hline Thalassiosira weissflogii & CCMP1336 & Gardiners lsland, Long Island, NY, LSA & $\mathrm{N}$ & + \\
\hline Thalassiosira oceanica & CCMP1005 & Sargasso Sea, $33^{\circ} 11^{\prime} \mathrm{N}, 65^{\circ} 15^{\prime} \mathrm{W}$ & $\mathrm{O}$ & + \\
\hline Minutocellus polymorphus & CCMP499 & Raritan Bay, Sandy Hook, NJ, USA & $\mathrm{N}$ & - \\
\hline Chaetoceros neogracile & Chaet B & Boothbay, ME, USA & $\mathrm{N}$ & + \\
\hline EqPac pennate diatom & $7-47 B$ & E. Equatorial Pacific Ocean & $\mathrm{O}$ & + \\
\hline EqPac pennate diatom & $10-40 \mathrm{~A}$ & E. Equatorial Pacific Ocean & $\mathrm{O}$ & + \\
\hline EqPac pennate diatom & A $3-30$ & E. Equatorial Pacific Ocean & $\mathrm{O}$ & + \\
\hline \multicolumn{5}{|l|}{ Prymnesiophyceae } \\
\hline Emiliania huxleyi & CCMP370 & Oslofjord, North Sea & $\mathrm{N}$ & + \\
\hline Emiliania huxleyi & CCMP373 & Sargasso Sea, $32^{\circ} 10^{\prime} \mathrm{N}, 64^{\circ} 30^{\prime} \mathrm{W}$ & $\mathrm{O}$ & + \\
\hline Syracosphaera elongata & CCMP874 & Unknown & $?$ & - \\
\hline Pleurochrysis carterae & CCMP645 & Woods Hole, MA, USA & $\mathrm{N}$ & - \\
\hline Phaeocystis sp. & CCMP1528 & Gardiner Bay, Galapagos Islands & $\mathrm{N}$ & + \\
\hline Chrysochromulina ericina & CCMP281 & N. Pacific, $49^{\circ} 36^{\prime} \mathrm{N}, 140^{\circ} 37^{\prime} \mathrm{W}$ & $\mathrm{O}$ & + \\
\hline \multicolumn{5}{|l|}{ Cyanophyceae } \\
\hline Synechococcus & CCMP1334 & Sargasso Sea, $33^{\circ} 44.9^{\prime} \mathrm{N}, 67^{\circ} 29.8^{\prime} \mathrm{W}$ & $\mathrm{O}$ & - \\
\hline
\end{tabular}

tures were adjusted according to the Fe requirements of individual clones. EDTA was added to iron-limited cultures at $1 \times 10^{-6} \mathrm{M}$. Organisms were transferred twice into the appropriate medium (iron-replete or iron-limited) in $25 \mathrm{ml}$ tubes before inoculation into experimental flasks. Cultures were grown in 2.81 Fernbach flasks containing $2 \mathrm{l}$ of medium and were maintained at 15,20 or $25^{\circ} \mathrm{C}$ under a $14 \mathrm{~h}$ light: $10 \mathrm{~h}$ dark cycle with illumination from 'cool white' fluorescent lights at approximately $150 \mu \mathrm{E} \mathrm{m} \mathrm{m}^{-2} \mathrm{~s}^{-1}$. Growth was monitored by microscope cell counts or Coulter counter (Coulter Instruments, Hialeah, FL, USA), and cultures were harvested by centrifugation when they reached late exponential phase. Cell pellets were frozen at $-80^{\circ} \mathrm{C}$ until analysis.

Culture conditions - nutrient regulation. Nutrientdeficient cultures were also grown in modified ESNW medium. Nitrogen-, phosphorus-, silica- and lightdeficient cultures of Thalassiosira weissflogii all contained $10 \mu \mathrm{M} F$ and $100 \mu \mathrm{M}$ EDTA. The control culture was enriched with $50 \mu \mathrm{M} F$ e and $500 \mu \mathrm{M}$ EDTA and iron-limited cultures contained $100 \mathrm{nM} F \mathrm{Fe}$ and $1 \mu$ M EDTA. Nitrate-, phosphate- and silicate-deficient cultures contained the limiting nutrient at $1 / 50$ the concentration of full medium, 11.0, 0.42 and $2.11 \mu \mathrm{M}$ respectively. Zinc-limited cultures were not grown by the authors, but were provided by Dr Jenny Lee as cells harvested onto $3 \mu \mathrm{m}$ polycarbonate filters and frozen in liquid nitrogen. Zinc-limited cells were grown in Aquil medium (Price et al. 1988/1989) with a calculated $\mathrm{pZn}=11.6$

Cultures (2 l volume) were grown in acid-washed glass or polycarbonate $2.8 \mathrm{l}$ Fernbach flasks. They were maintained at $20^{\circ} \mathrm{C}$ on a $14 \mathrm{~h} \mathrm{light:} 10 \mathrm{~h}$ dark cycle at a photon flux density of ca $175 \mu \mathrm{E} \mathrm{m} \mathrm{m}^{-2} \mathrm{~s}^{-1}$ as measured inside the culture flasks with a quantum irradiance meter (Biospherical Instruments model QSP-100). Light-limited cultures were covered with 3 layers of neutral density screening, resulting in a measured irradiance of ca $20 \mu \mathrm{E} \mathrm{m} \mathrm{m}^{-2} \mathrm{~s}^{-1}$. Cell densities were determined by 4 replicate microscopic counts of Utermöhl's preserved samples in a Fuchs-Rosenthal hemacytometer. Growth rates during exponential phase were calculated from linear regressions of the natural log of cell density versus time. Growth rates are expressed in the text as the mean $\pm 1 \mathrm{SE}$.

Control, Fe-limited and light-limited cultures were harvested during the mid-exponential phase of growth. Nitrogen-, phosphorus- and silica-deficient cultures were allowed to reach early stationary phase before harvest. At the appropriate stage (exponential or early stationary), subsamples were removed for chlorophyll determinations and cell counts. The remaining volume was collected onto $3 \mu \mathrm{m}$ polycarbonate filters (47 $\mathrm{mm}$ diameter), except for approximately $100 \mathrm{ml}$. This volume was used as an inoculum for the next culture, which was initiated by the addition of 21 of fresh culture medium. Three sequential cultures 
were grown in this manner for all treatments except the control culture which was grown once. After harvest, cells were frozen at $-80^{\circ} \mathrm{C}$ until analysis. While triplicate cultures were grown for all treatments except the control, representative data from only 1 round of culturing is presented here for simplicity.

Growth of phytoplankton-Fe limitation. Cultures of Thalassiosira weissflogii were grown by the procedure detailed in Maldonado \& Price (1996). Cultures were grown in the artificial culture medium Aquil (Price et al. 1988/1989) with minor modifications. Media contained standard enrichments of phosphate and silicate, with either $50 \mu \mathrm{M}$ nitrate or ammonium. Premixed Fe-EDTA (1:1) was added separately at a range of concentrations from $10 \mathrm{nM}$ to $8.4 \mu \mathrm{M}$, to achieve free ferric ion concentrations of $10^{-21} \mathrm{M}(\mathrm{pFe}$ $21.1)$ to $10^{-18.8} \mathrm{M}$ (pFe 18.8). Synthetic ocean water was sterilized by microwaving in acid-washed Teflon bottles (Keller et al. 1988) and enriched with sterile nutrients. Trace-metal-clean technique was employed for all cultures, as outlined by Price et al. (1988/1989).

Cultures were grown in acid-washed polycarbonate flasks. They were maintained at $20^{\circ} \mathrm{C}$ under continuous irradiance of $200 \mu \mathrm{E} \mathrm{m}^{-2} \mathrm{~s}^{-1}$, using the semi-continuous batch culture technique described by Brand et al. (1981). Growth rates were determined by measurements of in vivo fluorescence using a Turner Designs fluorometer (model 10-AU). Growth rates were calculated from linear regressions of the natural log of in vivo fluorescence versus time. Cultures were considered to be acclimated when growth rates of successive transfers did not vary by more than $10 \%$. Cells were harvested by filtration, stored in liquid nitrogen and subsequently lyophilized prior to analysis.

Chlorophyll a determinations. Chl $a$ in $\mathrm{N}-, \mathrm{P}-, \mathrm{Si}-$, $\mathrm{Fe}$ - and light-deficient cultures was measured on triplicate samples per flask. Cells were collected by gentle filtration onto Millipore SSWP membranes $(3 \mu \mathrm{m}$, $25 \mathrm{~mm}$ diameter) and frozen in liquid nitrogen until analysis. Filters were extracted in $100 \%$ acetone for $24 \mathrm{~h}$ at $4^{\circ} \mathrm{C}$ in the dark. Before measurement, samples were diluted to $90 \%$ acetone and allowed to warm to room temperature. Chlorophyll was measured fluorometrically using a Turner Designs fluorometer (model 10-AU). The fluorometer was calibrated using standards of pure chlorophyll a (Sigma Chemical Co, St. Louis, MO, USA), which were quantified spectrophotometrically using the extinction coefficients from Jeffrey \& Humphrey (1975).

Iron addition bioassays. For the phylogenetic survey, iron limitation at late exponential phase was determined in 2 ways: decrease in growth rate compared to replete culture grown in tandem, and $\mathrm{Fe}$ addition bioassay. For bioassays, $30 \mathrm{ml}$ aliquots of iron-limited culture were transferred to acid-cleaned polycarbonate tubes after which the remaining culture volume was harvested. One tube was kept as a control, a second was enriched with $\mathrm{Fe}$ to replete levels and the third was enriched with all nutrients except Fe. The tubes were incubated as above and growth was tracked by in vivo fluorescence.

Protein extraction. Initially, cell extracts were prepared by an acetone precipitation technique. Briefly, cells were washed from filters using extraction buffer (20 mM phosphate, $100 \mathrm{mM}$ EDTA, $100 \mathrm{mM} \mathrm{NaCl}$, $13 \mathrm{mM} \beta$-mercaptoethanol, $1 \mathrm{mM}$ PMSF pH 7.0) and lysed by the addition of 9 volumes of acetone. The resulting acetone precipitate was collected by centrifugation, dried and then resuspended in extraction buffer. This aqueous extract was analyzed for ferredoxin and flavodoxin by HPLC. All phylogenetic survey samples and half of the $\mathrm{N} / \mathrm{Fe}$ interaction samples were extracted using this method.

The remaining $\mathrm{N} / \mathrm{Fe}$ samples and all of the nutrient limitation samples were extracted using an alternative method. Cells and their filters were placed in a $2 \mathrm{ml}$ tube with ice-cold extraction buffer (described above) and zirconium beads. Cells were ruptured by three $50 \mathrm{~s}$ cycles in a mini-beadbeater (Biospec Instruments, Bartlesville, OK, USA) and placed on ice between cycles. The cell lysate was centrifuged for $1 \mathrm{~h}$ at $105000 \times g$ and the supernatant was filtered $(0.45 \mu \mathrm{m})$ and injected into the HPLC. Prior to use of this extraction method, it was compared to the acetone powder method using laboratory cultures of Thalassiosira weissflogii. The overall extraction efficiency using this alternative method was better, and the same ratio of ferredoxinflavodoxin was obtained from the 2 methods when using identical samples (data not shown).

HPLC of ferredoxin and flavodoxin. All cultures were analyzed using the HPLC method of Doucette et al. (1996). Ferredoxin and flavodoxin in cell extracts were separated by anion-exchange HPLC. Detection was performed with a Hewlett-Packard model 1050 diode array detector (Hewlett-Packard. $\mathrm{Co}$, Andover, MA, USA), which also allowed identification of the proteins by their absorption spectra. Quantification of peak areas was performed by HP ChemStation software (Hewlett-Packard) in autointegration mode. The zinc-limited samples, which were analyzed prior to the other cultures, are an exception to this procedure. The same chromatographic method was employed, but a Hewlett-Packard model 1040A diode array detector was used instead of model 1050. Model 1040A records wavelength data only in the range from $250 \mathrm{~nm}$ to $600 \mathrm{~nm}$, whereas model 1050 covers the range from $200 \mathrm{~nm}$ to $600 \mathrm{~nm}$. This is reflected in Fig. 5, where the spectrum of the chromatographic peak of the zinc sample begins at $250 \mathrm{~nm}$. The data collected by model 1040A were analyzed using the HP ChemStation pro- 
gram, thus quantification of peak areas was by the same method as for the other samples.

\section{RESULTS AND DISCUSSION}

Both flavodoxin (LaRoche et al. 1995, 1996) and the cellular ratio of ferredoxin:flavodoxin (Doucette et al. 1996) have been proposed as molecular markers of iron limitation in marine phytoplankton. This study seeks to extend our knowledge of ferredoxin and flavodoxin expression so that we may better assess their usefulness as a diagnostic test for iron limitation. The data show flavodoxin induction to be a common response to iron stress in marine phytoplankton. Furthermore, it is specific to iron limitation and insensitive to nitrate, phosphate, silicate, zinc and light deficiency, supporting its use as an indicator of the presence or absence of iron limitation. We also show that the usefulness of flavodoxin as a marker may be extended by measuring both it and ferredoxin together in a sample. The ratio of the 2 proteins varies with, and should thus indicate changes in, the severity of iron stress.

\section{Phylogenetic survey}

In total, 17 isolates representing 4 phytoplankton classes were examined for their ability to induce flavodoxin when limited by iron (Table 1). Ferredoxin and flavodoxin in cellular extracts were separated using HPLC and identified by their characteristic absorption spectra (Fig. 1), which allows unambiguous identification of the 2 proteins. The most common response $(12$ of 17 isolates) was an absence of flavodoxin under ironsufficient conditions, with induction of flavodoxin and suppression of ferredoxin expression occurring when the cells were iron-stressed. The remaining 5 organisms were never observed to express flavodoxin under either iron-replete or -limited conditions. It is evident from these data that flavodoxin induction is a common,
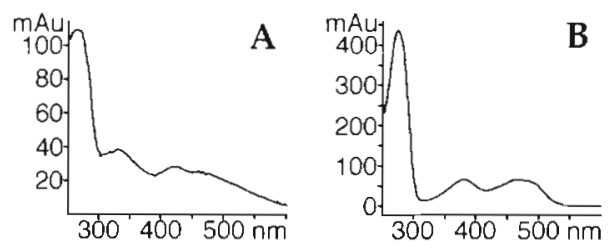

Fig. 1. UV-visible absorbance spectra of (A) ferredoxin and (B) flavodoxin from Thalassiosira weissflogii. In addition to the $280 \mathrm{~nm}$ absorbance maximum common to all proteins, ferredoxin exhibits secondary maxima at ca 330 and $430 \mathrm{~nm}$ and a shoulder at $465 \mathrm{~nm}$. Flavodoxin, in contrast, has secondary maxima at ca 365 and $465 \mathrm{~nm}$, giving it a distinctive 'camel hump' appearance but not universal, adaptation to iron limitation in marine phytoplankton. This heterogeneity in response is similar to that documented in freshwater algae, where ferredoxin and flavodoxin have been extensively studied. Given our results and those in the literature, flavodoxin induction in response to iron limitation seems to be the most typical and frequently observed response.

\section{Lack of flavodoxin induction}

A minority of the organisms examined (5 of 17) were never observed to produce flavodoxin. Regarding this group of 'non-inducers', a logical concern was that the cultures examined were not iron-limited. In ironlimited medium all exhibited decreased growth rates compared to replete control cultures, which is consistent with iron stress. (Synechococcus was grown by others for this analysis, so similar growth rate information is not available.)

Further evidence of iron limitation was obtained from nutrient addition bioassays (Fig. 2). While growth of primary cultures was monitored by cell counts, the bioassays were monitored by measurement of in vivo fluorescence. Positive bioassays were characterized by an increase in fluorescence only in Fe-enriched samples. In vivo chlorophyll fluorescence is known to be affected by iron stress, and its use may seem to con-
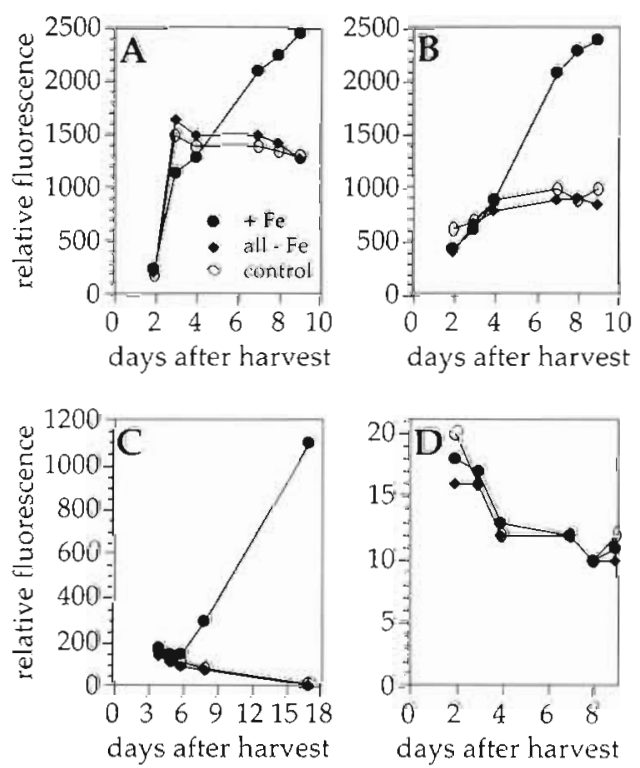

Fig. 2. (A) Syracosphaera elongata, (B) Pleurochrysis carterae, (C) Minutocellus polymorphus, (D) Alexandrium fundyense. Bioassay results from iron-limited cultures of species that did not express flavodoxin. Culture aliquots removed on the day of harvest were amended with either $\mathrm{Fe}(\bullet)$, all nutrients except Fe (•), or no addition (O) as a control. Growth was monitored by in vivo fluorescence 
found interpretation of the bioassay results. This is because the increase in fluorescence following iron addition can be accounted for in several ways. First higher fluorescence may be due to increases in chlorophyll per cell rather than an increase in cell number Second, it may be due to increased biomass due to cell growth and/or division in the culture. Finally, increases in fluorescence are observed when cells become ironlimited, because iron stress damages the photochemical apparatus and impairs electron transfer capability (Terry 1983). In a sample that has been enriched with iron, however, any enhanced fluorescence relative to the corresponding controls must be due to either increases in cell number or size, or in fluorescence per cell, both of which indicate that the original culture was limited by iron.

Syracosphaera elongata (Fig. 2a), Pleurochrysis carterae (Fig. 2b) and Minutocellus polymorphus (Fig. 2c), none of which induced flavodoxin, all exhibited positive growth responses when iron was added to aliquots of the iron-limited culture; the addition of other nutrients elicited no change. These cultures were clearly iron-limited. In contrast, one other non-inducing organism, Alexandrium fundyense, showed no obvious pattern of response in iron-addition bioassays when grown repeatedly under a variety of iron additions from $0 \mathrm{nM}$ to $1 \mu \mathrm{M}$ (data not shown). Nevertheless a marked decrease in specific growth rate $\left(\mu=0.325 \mathrm{~d}^{-1}\right.$ replete vs $0.073 \mathrm{~d}^{-1}$ low iron) was observed for $A$. fundyense cultured in low-iron medium. As all other culturing conditions were identical, the lack of iron must be responsible for the reduced growth rate for this dinoflagellate.

Lack of flavodoxin was not confined to a particular taxonomic group; examples were seen amongst the dinoflagellates, prymnesiophytes and diatoms in Table 1. It did, however, seem to occur primarily in coastally derived clones within a class. Of the 5 noninducing organisms in this study, 3 were isolated from neritic habitats while a fourth, Syracosphaera elongata, was of unknown origin. Phytoplankton from neritic versus oceanic habitats are known to exhibit different responses to trace metals. Neritic species generally suffer iron limitation at Fe levels far above those at which oceanic species show little or no impairment (Brand et al. 1983. Brand 1991). However, this does not mean that coastal species in general are noninducers. In fact, the majority of the neritic clones examined in this study expressed flavodoxin.

The results presented here agree well with published data on phytoplankton iron requirements. Brand (1991) measured high minimum iron requirements for the coastal coccolithophorids Syracosphaera elongata and Pleurochrysis carterae, and the cyanobacterium Synechococcus DC2, none of which produce flavo- doxin. Doucette et al. (1989) calculated extremely high minimum iron requirements for the red tide dinoflagellate Alexandrium fundyense, another non-inducer. Organisms that are unable to express flavodoxin seem to consistently exhibit elevated cellular requirements for iron. This implies that non-inducing organisms should not present a problem for field measurements utilizing ferredoxin and flavodoxin as indicators of iron stress. At low metal concentrations, the success of oceanic organisms compared to neritic ones is due to decreased cellular Fe requirements for growth, as opposed to more efficient uptake systems (Sunda et al. 1991). The substitution of flavodoxin for ferredoxin permits a reduction in cellular Fe quotas, as the former contains no iron while the latter requires 2 iron atoms per molecule. Thus, organisms that cannot express flavodoxin should be unable to persist in chronically low-iron oceanic environments, and therefore would be constrained in their distributions to more iron-rich coastal areas. In the analysis of samples from openocean, low-iron environments, non-expression of flavodoxin should therefore not be a large complication, as non-inducing species are unlikely to constitute a significant portion of the biomass in these areas due to their restricted growth at low iron levels.

\section{Flavodoxin expression in Thalassiosira weissflogii}

Results obtained from the centric diatom Thalassiosira weissflogii during this study were somewhat different than those reported previously (Doucette et al. 1996). Like most others, this species induced flavodoxin in response to iron limitation, with an accompanying suppression of ferredoxin expression. When grown in medium with $1 \mathrm{\mu M} F \mathrm{Fe}, T$. weissflogii produced similar amounts of both ferredoxin and flavodoxin (see Doucette et al. 1996), whereas the other organisms utilized here contained only ferredoxin when grown at this iron level. This led Doucette et al. to conclude that ferredoxin was constitutively expressed in this species. In the present study, it was found that flavodoxin expression was ultimately suppressed by increasing the added $\mathrm{Fe}$ in the culture to $60 \mu \mathrm{M}, 6$ times that of the common $\mathrm{f} / 2$ medium (Guillard \& Ryther 1962). Thus, low-level flavodoxin expression by $T$ weissflogii seemed to be the result of high $\mathrm{Fe}$ requirements rather than constitutive expression as previously reported.

\section{Growth of cells in light- or nutrient-deficient culture}

Growth curves for Thalassiosira weissflogii cultures are displayed in Fig. 3. For the nutrient- or light-defi- 

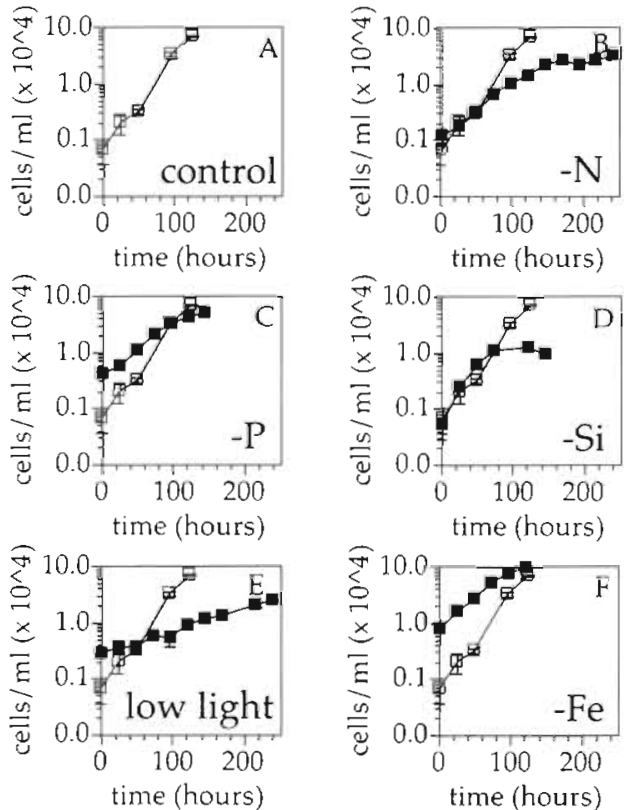

Fig. 3. Growth of (A) control, (B) nitrate-, (C) phosphate-, (D) silicate- (E) light- and (F) iron-deficient cultures of Thalassiosira weissflogii. (-) (ell numbers for treated cultures, (a) control cell numbers. For nutrient- and light-deficient cultures, cell numbers of the control culture are included for comparison

cient cultures (Fig. 3B-F), data from the control culture are included for comparison. The control culture was grown in complete medium and harvested during mid-exponential phase and was considered to be nonlimited. The $-\mathrm{N},-\mathrm{P}$ and $-\mathrm{Si}$ cultures were harvested for analysis during stationary phase, when the medium should have been effectively depleted of the limiting nutrient. The final biomass levels of the N- (Fig. 3B), P. (Fig. 3C) and Si-deficient (Fig. 3D) cultures at stationary phase were below that achieved by the control culture, characteristic of nutrient starvation. In theory, the growth rates of these 3 cultures should have been similar to that of the control during exponential phase, prior to the onset of nutrient limitation. The exponential growth rates for $\mathrm{N}_{-}, \mathrm{P}_{-}$, and Si-starved cultures, however, were lower than the control culture $\left(\mu=0.014 \pm 0.002,0.022 \pm 0.003\right.$ and $0.027 \pm 0.008 \mathrm{~h}^{-1}$. respectively), which suggests that the cells may have experienced some limitation by low nutrient availability before reaching stationary phase. The -Fe (Fig. 3F), -Zn and low light (Fig. 3E) cultures were harvested during exponential phase, during which their growth was constrained by the supply rate of the limiting factor. These cultures exhibited slowed but exponential growth rates relative to the control $(\mu=0.010 \pm 0.001$, $0.019 \pm 0.008$ and $0.038 \mathrm{~h}^{-1}$, respectively), indicative of light or iron limitation.

\section{Effect of nutrients and light on cellular chlorophyll levels}

Further evidence of limitation or starvation was provided by cellular chlorophyll measurements (Fig. 4). Chlorosis is a common effect of nitrogen, phosphorus and iron stress (e.g. Glover 1977, Laws \& Bannister 1980). This was evident in N-, P- and Fe-deficient cultures, whose cellular chlorophyll content was only 29,70 and $59 \%$ of the level in control cells, respectively. The low-light grown cells exhibited increased pigment content $(170 \%$ relative to the control), a characteristic adaptation to limiting light levels (e.g. Laws \& Bannister 1980). Increased chlorophyll per cell (260\% of control level) was also measured in the Sistarved cells, consistent with silica starvation (Harrison et al. 1977).

\section{Effect of nutrients and light on ferredoxin and flavodoxin expression}

HPLC chromatograms, including UV-visible spectra of peaks, of cell extracts from nutrient-and light-deficient Thalassiosira weissflogii cells are shown in Fig. 5. The total range of the elution times was less than $1 \mathrm{~min}$, with the exception of the zinc-limited sample. It was analyzed some months prior to the other samples and exhibited a shifted elution time as well as a truncated UV-visible spectrum (see 'Materials and Methods'). In all cases, only 1 chromatographic peak was observed during the appropriate range of elution time. Flavodoxin was observed only in iron-limited cells (Fig. 5G), and was not induced in response to nitrogen, phosphorus, silica, zinc or light stress.

It has been shown previously that flavodoxin in Phaeodactylum tricornutum is not induced in response to nitrogen or phosphorus starvation (LaRoche et al. 1993). These data provide an independent confirma-

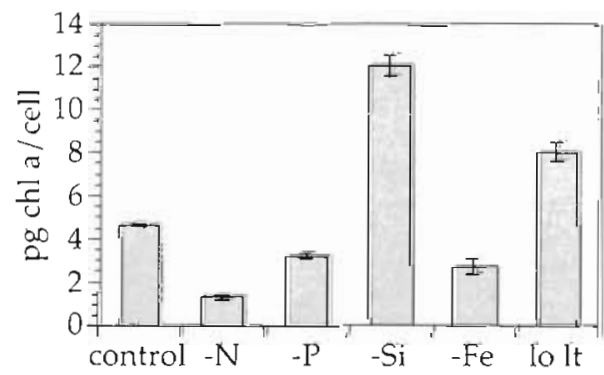

Fig. 4. Chlorophyll $a$ in pg cell ${ }^{-1}$ for the various nutrient treatments. Chl $a$ in the control was determined from triplicate subsamples of 1 culture. Values from all other conditions are pooled measurements of triplicate samples from each of 3 replicate cultures. Values shown are mean $\pm 1 \mathrm{SE}$ 


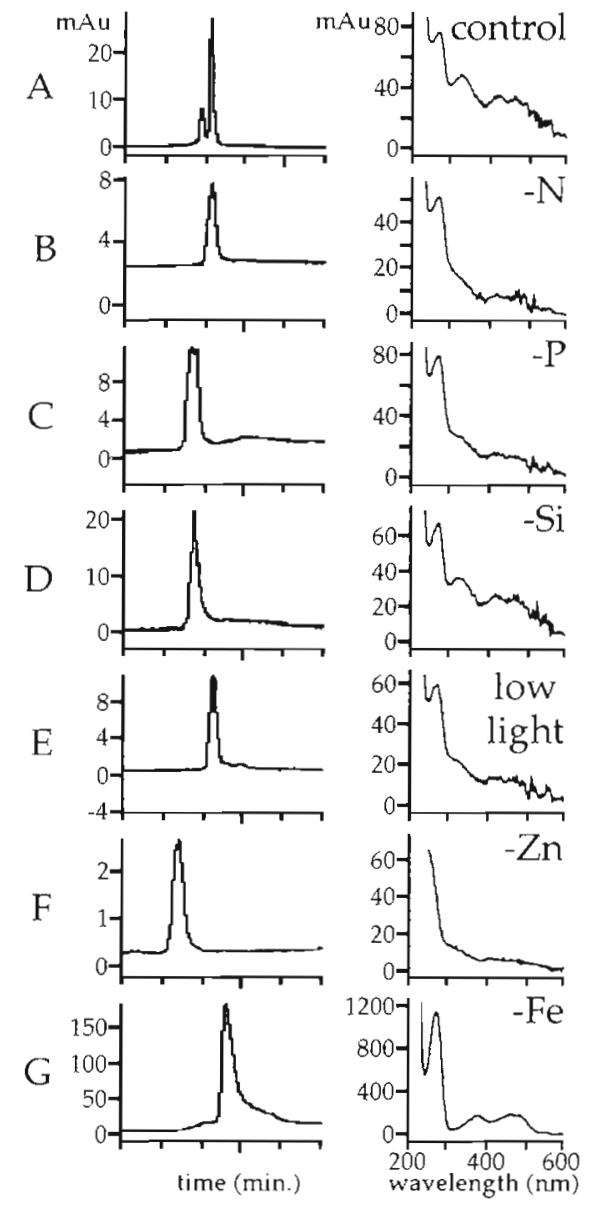

Fig. 5. (A-G) HPLC chromatograms of cell extracts of cultures grown under various limiting conditions. Compounds were detected by their absorbance at $465 \mathrm{~nm}$ (in mAu, vertical axis). The chromatograms have been cropped to show the relevant $10 \mathrm{~min}$ window during which ferredoxin and flavodoxin both elute. The UV-visible absorption spectrum of the peak is shown next to its corresponding chromatogram (A) control, (B) N-starved, (C) P-starved, (D) Si-starved, (E) light-limited, (F) zinc-limited and $(G)$ iron-limited. Whereas A-F all exhibit the ca 330 and $430 \mathrm{~nm}$ maxima of ferredoxin, only $\mathrm{G}$ has the characteristic flavodoxin 'camel hump'

tion of those results in a different species and extends our knowledge of ferredoxin and flavodoxin regulation to include the effects of silica-, zinc- and light-deficiency. Our intent was to examine some common forms of limitation that cells may be likely to encounter in natural waters.

In many potentially iron-limited regions of the ocean, there is also the possibility of limitation by other factors. Nitrogen or phosphorus stress is unlikely in the high-nutrient-low-chlorophyll areas of the ocean where iron limitation is suspected, but it may be a factor in coastal regions where macronutrient levels are often low and iron availability may vary both temporally and spatially (Wells et al. 1991). Another macronutrient, silicate, may be the 'next' limiting nutrient for diatoms in iron-limited areas, whose growth seems to be favored by iron enrichment (Coale et al. 1996). Oceanic regions with low surface water iron concentrations also typically exhibit low levels of other biologically important micronutrients such as zinc and manganese (Bruland et al. 1978, Landing \& Bruland 1980, Gordon et al. 1982). In the Southern Ocean, where iron limitation is one possible explanation for persistent HNLC conditions, light is also thought to constrain primary production (de Baar et al. 1990, Mitchell et al. 1991). Induction of flavodoxin by any of the aforementioned factors would generate 'false positives' for iron limitation. The insensitivity of flavodoxin to these potential limiting factors makes it an excellent candidate for a marker of iron limitation.

\section{Iron regulation of relative ferredoxin and flavodoxin abundance}

The effect of iron availability on relative ferredoxin and flavodoxin levels was investigated in detail by measuring the 2 proteins in cells grown over a range of iron concentrations (Fig. 6). Relative ferredoxin/flavodoxin abundance is expressed as the Fd index, defined as the proportion of ferredoxin in the combined ferredoxin + flavodoxin pool:

$$
\mathrm{Fd} \text { index }=\text { [ferredoxin } / \text { /ferredoxin + flavodoxun] }
$$

This expression is a modification of Eq. (1) of Doucette et al. (1996). The Fd index is calculated from the integrated HPLC peak areas, which are directly proportional to moles of ferredoxin or flavodoxin, and varies from 1 (only ferredoxin, no flavodoxin) to 0 (only flavodoxin, no ferredoxin). In Fig. 6 the Fd index is shown as a function of growth rate, which is expressed as a percentage of the known maximum rate and serves as a

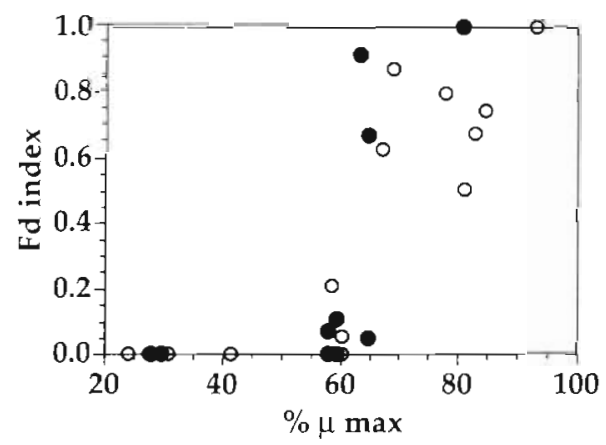

Fig. 6. Cellular ferredoxin/flavodoxin content over a range of iron-limited growth rates. Cells were grown on ( $\bullet$ nitrate or (0) ammonium. Fd index $=[$ ferredoxin/(ferredoxin + flavodoxin)] 
proxy for iron availability. When working with very low culture iron levels, small amounts of contamination can have a large effect on medium iron content. The culture growth rate is therefore a more accurate measure of the amount of iron actually present in the culture, rather than moles of iron added or calculated free ion activities.

It is interesting to note that while the cultures analyzed in Fig. 6 were grown on different $N$ sources, it did not seem to have any gross effect on ferredoxin/flavodoxin content. Nitrate-grown cells are thought to require more iron than those utilizing ammonium (Raven 1988) which should be reflected in their cellular iron quota. We hypothesized that cells may compensate for this increased cellular demand through changes in relative ferredoxin/flavodoxin content. However, the data in Fig. 6 show no obvious differences in response between nitrate- and ammoniumgrown cells. This is consistent with the results of Maldonado \& Price (1996), who demonstrated that nitrate-grown cells do have elevated cellular iron quotas relative to ammonium-grown cells but are able to compensate by acquiring more iron. Thus, the cells seem to satisfy their increased iron demands through uptake of extracellular iron rather than via reapportionment of the internal iron pool.

The results presented in Fig. 6 provide a description of changes in cellular ferredoxin and flavodoxin abundance in response to iron availability. At the highest growth rate examined here, which was near-maximal, cells expressed only ferredoxin ( $F d$ index $=1$ ). As iron availability and therefore growth rate decreased, cells contained less ferredoxin relative to flavodoxin $(0<$ Fd index < 1). Eventually, ferredoxin expression was completely repressed and cells contained only flavodoxin ( $F d$ index $=0$ ). Flavodoxin expression seemed to be very sensitive to iron limitation, being induced at relatively high growth rates $\left(80\right.$ to $\left.90 \% \mu_{\max }\right)$. The sensitivity of flavodoxin induction is in agreement with the results of McKay et al. (1997), who observed increases in flavodoxin protein ${ }^{-1}$ when cells were only mildiy iron-stressed $\left(\% \mu_{\max } \sim 80 \%\right)$. At intermediate iron levels, many of the cultures examined in our study contained both ferredoxin and flavodoxin in varying proportions. The cultures were grown semicontinuously and were therefore in a relative steady state, implying that replacement of ferredoxin by flavodoxin was a gradual process, not a simple 'on-oroff' response.

The relationship between Fd index and growth rate in Thalassiosira weissflogi is composed of 2 general regions. In the first region, below approximately $55 \% \mu_{\max }$ cells are experiencing moderate to severe stress, ferredoxin is undetectable and the Fd index is uniformly zero. In the second region, at moderate to low iron stress (high $\% \mu_{\max }$ ), ferredoxin and flavodoxin cooccur in the cells. In this latter region faster-growing cells tend to have higher Fd indices, which suggests that the Fd index is (logically) related to iron availability. Thus, the Fd index should provide information not only about the presence or absence of iron limitation, but also its relative severity.

This data is not intended to imply a universal relationship between growth rate and Fd index for all organisms. Growth rate is simply the most convenient way to quantify iron availability or iron stress in this analysis. The range of growth rates is intended to represent the continuum of iron stress, from fully replete to extremely deplete, and should be treated as such. The Fe levels required for iron-replete growth $\left(\mu_{\max }\right)$ will be different for different organisms, as will the amount required for survival (the lowest $\% \mu_{\max }$ ). Each organism will establish its own 'endpoints', but the response in between these limits should be similar. Regardless of cellular Fe quota, if Fe availability decreases below that required level, cells should progressively replace their ferredoxin with flavodoxin, eventually repressing all ferredoxin expression. It is not necessary to consider each cell's individual Fe quota, as the cell, in essence, does it for you. This exploits one of the strengths of molecular markersthey allow the cell to act as a reporter of the environmental conditions that it perceives.

\section{CONCLUSIONS}

The data presented here support the proposed role for ferredoxin and flavodoxin as a specific and sensitive system for the detection of iron limitation. Flavodoxin induction is an iron-specific response that is common amongst marine phytoplankton, and thus an excellent indicator of the presence or absence of iron limitation. Additional information may be gained by measuring the relative cellular abundance of ferredoxin and flavodoxin together, expressed here as the Fd index. The cellular Fd index varies with external iron availability and should indicate changes in the severity of iron stress. Thus, use of the 2 proteins together may allow determination of both temporal and spatial changes in iron stress, e.g. over the course of a phytoplankton bloom or on a transect from coastal to oceanic waters

Acknowledgements. This work was supported by a Graduate Fellowship for Global Change (D.L.E.), an Exploratory Research Agreement No. RP8021-05 from the Electric Power Research Institute (D.M.A.) and an NSERC Postdoctoral Fellowship and U.S. National Research Council-NOAA/NMFS Research Associateship (G.J.D.). Contribution no. 9878 from the Woods Hole Oceanographic Institution. 


\section{LITERATURE CITED}

Brand LE (1991) Minimum iron requirements of marine phytoplankton and the implications for the biogeochemical control of new production. Limnol. Oceanogr 36 $1756-1771$

Brand LE, Sunda WG, Guillard RRL (1983) Limitation of marine phytoplankton reproductive rates by zinc, manganese and iron. Limnol Oceanogr 28:1.182-1198

Bringloe DT, Dyer TA, Gray JC (1995) Developmental, circadian and light regulation of wheat ferredoxin gene expression. Plant Mol Biol 27:293-306

Bruland KW, Knauer GA, Martin JH (1978) Zinc in north-east Pacific water. Nature 271:741-743

Buma AGJ, de Baar HJW, Nolting RF, van Bennekom AJ (1991) Trace metal enrichment experiments in the Weddell-Scotia seas: effects of iron and manganese on various plankton communities. Limnol Oceanogr 36: $1865-1878$

Coale KH (1991) Effects of iron, manganese, copper, and zinc enrichments on productivity and biomass in the subarctic Pacific. Limnol Oceanogr 36:1851-1864

Coale KH and 18 others (1996) A massive phytoplankton bloom induced by an ecosystem-scale iron fertilization experiment in the equatorial Pacific Ocean. Nature 383:495-501

Cullen JJ (1991) Hypotheses to explain high-nutrient conditions in the open sea. Limnol Oceanogr 36:1578-1599

de Barar HJW, Buma AGJ, Nolting RF, Cadée GC, Jacques G, Tréquer PJ (1990) On iron limitation of the Southern Ocean: experimental observations in the Weddell and Scotia Seas. Mar Ecol Prog Ser 65:105-122

Dobres MS, Elliott RC, Watson JC, Thompson WF (1987) A phytochrome regulated pea transcript encodes ferredoxin. I. Plant Mol Biol 8:53-59

Doucette GJ, Cembella AD, Boyer GL (1989) Cyst formation in the red tide dinoflagellate Alexandrium tamarense (Dinophyceae): effects of iron stress. J Phycol 25:721-731

Doucette GJ, Erdner DL, Peleato ML, Hartman JJ, Anderson DM (1996) Quantitative analysis of iron-stress related proteins in Thalassiosira weissflogii: measurement of flavodoxin and ferredoxin using HPLC. Mar Ecol Prog Ser 130: $269-276$

Falkowski PG, Greene RM, Geider RJ (1992) Physiological limitations on phytoplankton productivity in the oceans. Oceanography 5:84-91

Fillat MF, Sandmann G, Gomez-Moreno C (1988) Flavodoxin from the nitrogen-fixing cyanobacterium Anabaena PCC 7119. Arch Microbiol 150:160-164

Fulda S, Hagemann M (1995) Salt treatment induces accumuIation of flavodoxin in the cyanobacterium Synechocystis sp. PCC 6803. J Plant Physiol 146:520-526

Glover $H$ (1977) Effects of iron deficiency on Isochrysis galbana (Chrysophyceae) and Phaeodactylum tricornutum (Bacillariophyceae). J Phycol 13:208-212

Gordon RM, Martin JH, Knauer GA (1982) Iron in north-east Pacific waters. Nature 299:611-612

Guillard RRL, Ryther JH (1962) Studies of marine plankton diatoms. I. Cyclotella nana (Hustedt) and Detorula confervacea (Cleve). Can J Microbiol 8:229-239

Harrison PJ, Holmes RW, Davis CO (1977) Marine diatoms grown in chemostats under silicate or ammonium limitation. III. Cellular chemical composition and morphology of Chaetoceros debilis, Skeletonema costatum, and Thalassiosira gravida. Mar Biol 43:19--31

Jeffrey SW, Humphrey CiF (1.975) New spectrophotometric equations for determining chlorophylls $a_{1} b_{1} c_{1}$ und $c_{2}$ in higher plants, algae and natural phytoplankton. Biochem Physiol Pflanzen 167:191-194

Keller MD, Bellows WK, Guillard RRL (1988) Microwave treatment for the sterilization of phytoplankton culture media. J Exp Mar Biol Ecol 117:279-283

Landing WM, Bruland KW (1980) Manganese in the North Pacific. Earth Planet Sci Lett 49:45-56

LaRoche J, Geider RJ, Graziano LM, Murray H, Lewis K (1993) Induction of specific proteins in eukaryotic algae grawn under iron-, phosphorous-, or nitrogen-deficient conditions. J Phycol 29:767-777

LaRoche J, Surray $H_{1}$ Orellana M, Newton J (1995) Flavodoxin expression as an indicator of iron limitation in marine diatoms. J Phycol 31:520-530

LaRoche J, Boyd PW, McKay RM, Geider RJ (1996) Flavodoxin as an in situ marker for iron stress in phytoplankton. Nature 382:802-805

Laws EA, Bannister TT (1980) Nutrient-and light-limited growth of Thalassiosira fluviatilis in continuous culture, with implications for phytoplankton growth in the ocean. Limnol Oceanogr 25:457 473

Maldonado MT, Price NM (1996) Influence of N substrate on Fe requirements of marine centric diatoms. Mar Ecol Prog Ser 141:161-172

Martin JH, Fitzwater SE (1988) Iron deficiency limits phytoplankton growth in the north-east Pacific subarctic. Nature $331: 341-343$

Martin $\mathrm{JH}$ (1990) Glacial-interglacial $\mathrm{CO}_{2}$ change: the iron hypothesis. Paleoceanography 5:1-13

Martin JH, Gordon RM, Fitzwater S, Broenkow WW (1989) VERTEX: phytoplankton/iron studies in the Gulf of Alaska. Deep-Sea Res 36:649-680

Martin JH, Broenkow WW, Fitzwater SE, Gordon RM (1990a) Yes, it does: a reply to the comment by Banse. Limnol Oceanogr 35:775-777

Martin JH, Gordon RM, Fitzwater SE (1990b) Iron in Antarctic waters. Nature 345:156-158

Martin JH and 43 others (1994) Testing the iron hypothesis in ecosystems of the equatorial Pacific ocean. Nature 371: $123-129$

McKay RML, Geider RJ, LaRoche J (1997) Physiological and biochemical response of the photosynthetic apparatus of two marine diatoms to Fe stress. Plant Physiol 114:615-622

Mitchell GB, Brody EA, Holm-Hansen O, McClain C, Bishop $\mathrm{J}$ (1991) Light limitation of phytoplankton biomass and macronutrient utilization in the Southern Ocean. Limnol Oceanogr 36:1662-1677

Pardo MB, Gómez-Moreno C, Peleato ML (1.990) Effect of iron deficiency on ferrodoxin levels in Anabaena variabilis PCC 6309. Arch Mikrobiol 153:528-530

Price NM and 6 others (1988/1989) Preparation and chemistry of the artificial algal culture medium. Aquil Biol Oceanogr $6: 443-461$

Raven JA (1988) The iron and molybdenum use efficiencies of plant growth with different energy, carbon, and nitrogen sources. New Phytol 109:279-287

Sandmann G, Peleato ML, Fillat MF, Lázaro MC, Gómez-Moreno $C(1990)$ Consequences of the iron-dependent formation of ferredoxin and flavodoxin on photosynthesis and nitrogen. fixation on Anabaena strains. Photosynth Res 26:119-125

Sunda WG, Swift DG, Huntsman SA (1991) Low iron requirement for growth in oceanic phytoplankton. Nature 351 : $55-57$

Terry N (1983) Limiting factors in photosynthesis. IV. Iron stress-mediated changes in light-harvesting and electron transport capacity and its effects on photosynthesis in vivo. Plant Physiol 71:855-860 
Venrick EL, Beers JR, Heinbokel JF (1977) Possible consequences of containing microplankton for physiological rate measurements. J Exp Mar Biol Ecol 26 . $55-76$

Vetter H, Knappe J (1971) Flavodoxin and ferredoxin of Escherichia coli. Z Physiol Chem 352:433-446

Editorial responsibility: Otto Kinne (Editor),

Oldendorf/Luhe, Germany
Wells ML, Mayer LM, Guillard RRL (1991) A chemical method for estimating the availability of iron to phytoplankton in seawater. Mar Chem 33:23-40

Zumft WG, Spiller H (1971) Characterization of a flavodoxin from the green alga Chlorella. Biochern Biophys Res Comm 45: $112-118$

Submitted: October 8, 1998; Accepted: February 10, 1999 Proofs received from author(s): July 7, 1999 